\title{
Greenland ice sheet melt area from MODIS (2000-2014)
}

\author{
Robert S. Fausto, Dirk van As, Jens A. Antoft, Jason E. Box, William Colgan and the PROMICE \\ project team*
}

The Greenland ice sheet is an excellent observatory for global climate change. Meltwater from the 1.8 million $\mathrm{km}^{2}$ large ice sheet influences oceanic temperature and salinity, nutrient fluxes and global sea level (IPCC 2013). Surface reflectivity is a key driver of surface melt rates (Box et al. 2012). Mapping of different ice-sheet surface types provides a clear indicator of where changes in ice-sheet surface reflectivity are most prominent. Here, we present an updated version of a surface classification algorithm that utilises NASA's Moderateresolution Imaging Spectroradiometer (MODIS) sensor on the Terra satellite to systematically monitor ice-sheet surface melt (Fausto et al. 2007). Our aim is to determine the areal extent of three surface types over the 2000-2014 period: glacier ice, melting snow (including percolation areas) and dry snow (Cuffey \& Paterson 2010). Monthly $1 \mathrm{~km}^{2}$ resolution surface-type grids can be downloaded via the CryoClim internet portal (www.cryoclim.net). In this report, we briefly describe the updated classification algorithm, validation of surface types and inter-annual variability in surface types.

\section{Classification algorithm}

The algorithm uses normalised thresholds (Th) from calibrated radiances (MOD021KM) between the near-infrared band 5 (1230-1250 nm) and the visible band 10 (483$493 \mathrm{~nm}$ ). This updated classification improves on Fausto et al. (2007) by implementing new surface type thresholds: $\mathrm{Th}_{\text {dry snow }} \leq 0.86,0.86<\mathrm{Th}_{\text {melting snow }}<0.94$ and $T \mathrm{~T}_{\text {glacier }}$ ice $\geq 0.94$. Data gaps can be caused by cloud cover, which is identified from the MOD35_L2. The ratio between band 1 $(620-670 \mathrm{~nm}$, red visual) and band $7(2105-2155 \mathrm{~nm}$, shortwave infrared) as well as the magnitude of band 1 are used to identify non-glacierised terrain (Fausto et al. 2007).

Daily classification scenes are aggregated to yield a monthly Greenland surface type (GST) product. For the GST product, pixels are classified according to their most frequently occurring (cloud-free) colour during a month. The maximum melt extent (GSTmax) is defined by a given pixel classified as melting or bare ice. The pixel class must occur at

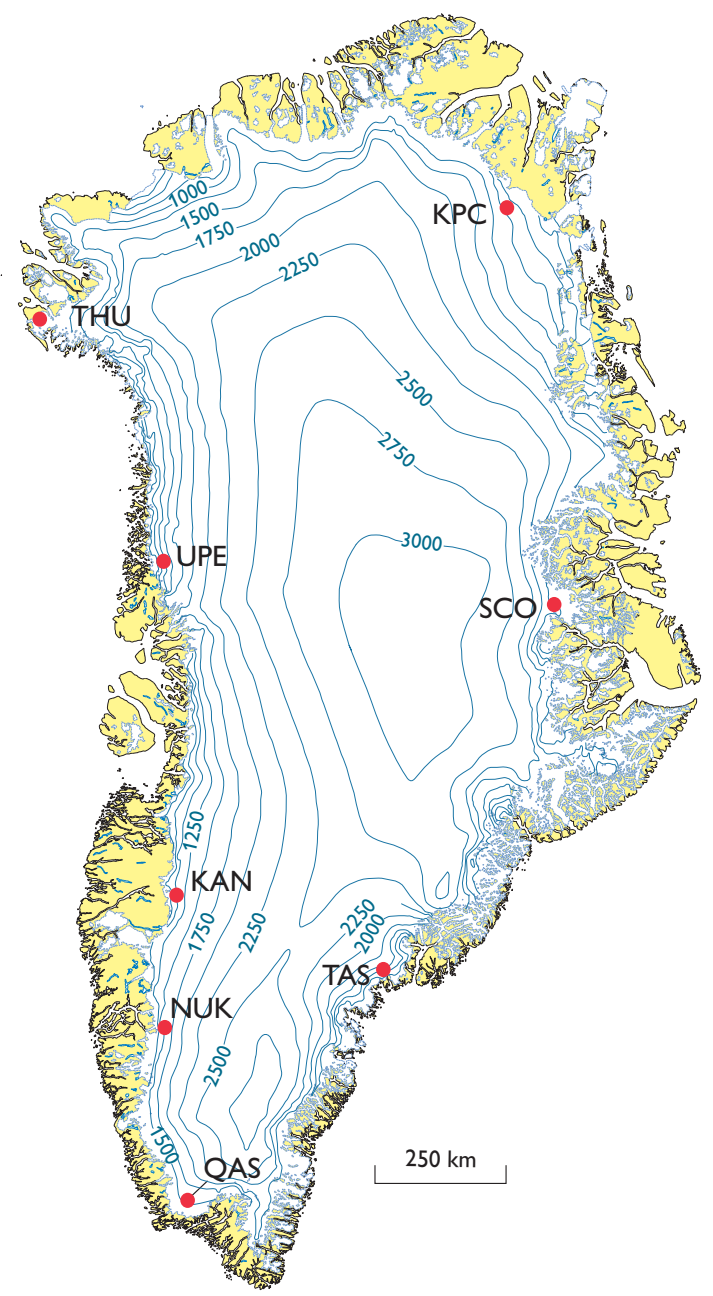

Fig. 1. Greenland map showing the locations of PROMICE automatic weather stations. Each dot represents two or three stations. Elevation contours in metres.

least one day per month. The GSTmax product thus contains information about brief melt events. Conversely, a minimum melt extent (GSTmin) is calculated from pixels classified as dry snow at least once per month. Pixels from areas not cov-

\footnotetext{
* Signe B. Andersen, Andreas P. Ahlstrøm, Morten L. Andersen, Michele Citterio, Charalampos Charalampidis, Karen Edelvang, Konstanze Haubner, Signe H. Larsen, Martin Veicherts and Anker Weidick
} 
ered by ice are excluded from Greenland melt area calculations employing the melting snow and glacier ice types in the GST, GSTmax, and GSTmin products (Fausto et al. 2007).

\section{Validation}

The PROMICE automatic weather station (AWS) network currently consists of eight regions each with two or three stations at a variety of low elevations on the Greenland ice sheet (Fig. 1; Ahlstrøm et al. 2008; Citterio et al. 2015). Most stations are located in the ablation area, and are thus transitioning from snow-covered to bare ice surfaces through the melt season. Each station records a suite of meteorological and glaciological measurements, including ice temperature to $10 \mathrm{~m}$ depth and surface height changes due to accumulation or ablation (Citterio et al. 2015).

To validate the three surface types we classify, we use daily mean surface albedo $(\alpha)$, the ratio between incoming and outgoing solar radiation and surface temperature $(T)$ data for the 2008-2014 period from the AWS. Based on $\alpha$ and $T$, we define three classifications for AWS sites: dry snow $\left(\alpha>0.7\right.$ or $\left.T<-7^{\circ} \mathrm{C}\right)$, melting snow $(0.7>\alpha>0.55)$, and glacier ice $(\alpha<0.55$; Cuffey \& Paterson 2010). Employing the $T$ criterion acknowledges the influence of diurnal cycles at the beginning of the melt season. As a validation example, the in situ albedo and nearest-pixel classification at KAN_L in 2009 are presented in Figs 2 and 3, including a visual comparison with the passive microwave melt area product (PMP) by Mote (2007).

The KAN_L station, located $c .10 \mathrm{~km}$ from the ice sheet margin at $680 \mathrm{~m}$ elevation, transitions through all three surface types during the melt season, from dry snow to melting
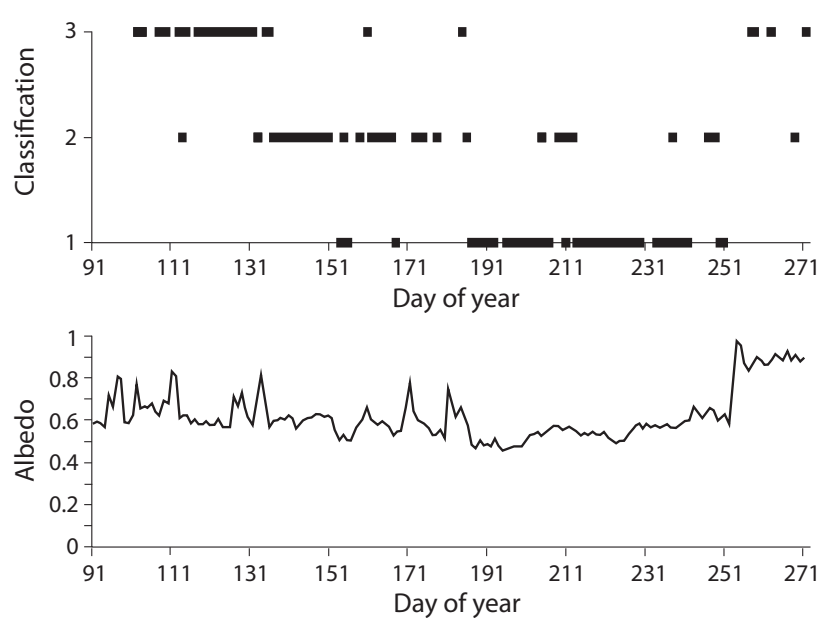

Fig. 2. Daily GST classification for 2009 of the KAN_L pixel and albedo measured at the KAN_L automatic weather station. 1: glacier ice. 2: melting snow. 3: dry snow.
Table 1. Error matrix for the assessment of KAN_L

\begin{tabular}{lcccc}
\hline GSTIAWS* & Glacier ice & Melting snow & Dry snow & Total \\
\hline Glacier ice & 32 & 14 & 0 & 46 \\
Melting snow & 3 & 33 & 1 & 37 \\
Dry snow & 0 & 5 & 21 & 26 \\
\hline
\end{tabular}

* GST: Greenland surface type

AWS: automatic weather station

snow to glacier ice. Relative to the 2000-2014 period, the 2009 surface melt was normal in west Greenland, with maximum melt areal extent in August. At KAN_L, the surface melted from May to August, with a daily mean albedo generally between 0.5 and 0.6 (Fig. 2). The algorithm accuracy for the KAN_L site may be assessed by an error matrix (Table 1). The diagonal represents successful classifications, the total number represents all classifications and the ratio between the sum of the diagonal and total is the accuracy. The algorithm yields $79 \%$ successful classifications at KAN_L, with an overall accuracy of $71 \%$. The classification algorithm performs best in the south and worst in the north, with accuracies of $87 \%$ (NUK_L) and 61\% (KPC_U), respectively. Figure 2 illustrates changes in surface type during summer 2009, between 15 May and 14 September, according to the AWS data; all but two classifications were successful.

\section{Results and discussion}

The melt area from this algorithm and the PMP of Mote (2007), illustrated in Fig. 3 for 12 July 2012, are consistent with the reported melt area by Nghiem et al. (2012), who documented that $98.6 \%$ of the ice-sheet surface had melting. The GST also demonstrates close visual correspondence with PMP for the 2000-2014 MODIS period (Fig. 4). In Fig. 4 we have plotted the yearly maximum values of the GST, GSTmax and GSTmin products, as well as the PMP maximum extent of Greenland melt area. The increasing trends of GSTmax and GSTmin indicate a rising frequency of melt events and increasing summer melt, which is corroborated by the PMP which is comparable with GSTmax. The trend for PMP between 1979 and 2000 and 2000 and 2012 are almost identical making the PMP and GSTmax trends comparable. Overall, an expansion of the melt area to higher elevations is apparent (Fig. 4).

Fausto et al. (2007) suggested that a sub-monthly GST product is non-optimal, because missing data due to cloud cover is the primary problem in determining the melt area. When trying to characterise all of Greenland, Hall et al. (2012) also found clear-sky, day-count problems, and also suggested that a sub-monthly product would have significant uncertainty. However, uncertainties associated with the dif- 

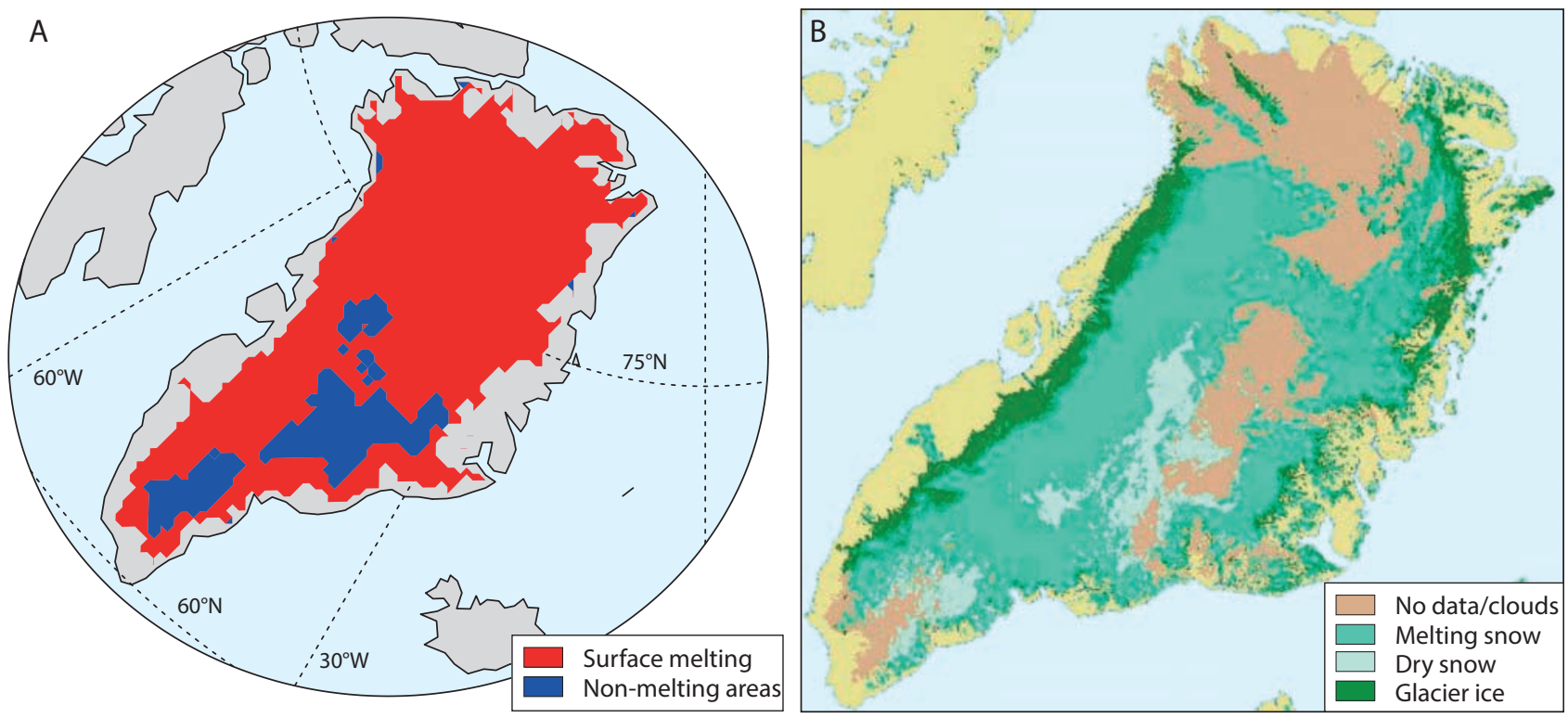

Fig. 3. Melt area on the Greenland ice sheet for 12 July 2012 A: Passive microwave melt area product (PMP). B: Greenland surface type classification.

ferent surface types are assessed with the number of observations and standard deviation for each cloud-free pixel of the GST product (Fausto et al. 2007). The MODIS data have the advantages of high spatial resolution $\left(1 \mathrm{~km}^{2}\right)$, pan-ice sheet coverage and quasi-daily temporal coverage, while the footprints of the in situ measurements are small. The AWS surface type classifications are therefore not an ideal ground truth for the surface classification. Furthermore, whereas both GST and PMP melt area products can give daily results, the PMP surface microwave emittance originates not only from the surface but the top metre of the snow or firn, and is influenced by the water content in the snow during the previous days (Mote 2007). MODIS classification is sensitive to cloud cover, but the spatial resolution of PMP is 625 times coarser than GST. During the melt period, exposed glacier ice in the ablation zone can have sub-zero temperatures. Such areas are included in the melting area, because the algorithm only makes use of the visual and near-infrared spectrum. Hence the melt area that we map might be more representative of the cumulative melt area during the melt period. However, if exposed, glacier ice in the ablation zone is covered by snow it will be mapped as non-melting areas.

An August anomaly in monthly GST is evident during the 2010-2014 period. All August images indicate a noisy melting snow classification in the northern ice sheet (not shown), which is most likely due to false classification. However, anomalous, high concentrations of dust or reddish material have been observed on the ice sheet during recent late summers (Dumont et al. 2014). Increasing dust concentra- tions are problematic for the fixed threshold algorithm we employ, because of enhanced absorption in near infrared wavelengths. Despite this possible biased source, an increasing trend in the melt area for the MODIS and PMP periods (Fig. 4) is consistent with increasing Greenland mass loss due to surface processes (Tedesco et al. 2013). Both independent, remotely sensed observations (Hall et al. 2012) and in situ observations (McGrath et al. 2013) show that the Greenland melt area is expanding to higher elevations.

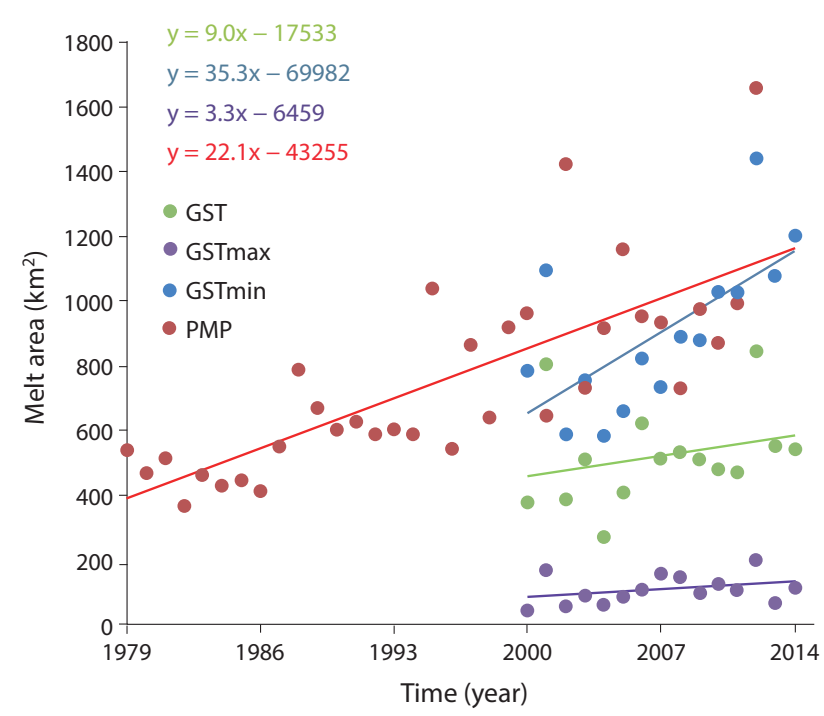

Fig. 4. Yearly maximum melt area values and trends according to Greenland surface type (GST), maximum melt extent (GSTmax), minimum melt extent (GSTmin) and passive microwave melt area product (PMP). 


\section{Conclusions}

The MODIS data can yield daily, automated classifications of the Greenland ice sheet into bare ice, melting and dry snow areas. Validation indicates that the surface classes are useful as ice-sheet climate indicators. The surface-type products are complementary to existing ice-surface temperature (Hall et al. 2012) and melt-area (Mote 2007) products.

\section{Acknowledgements}

The Programme for Monitoring of the Greenland Ice Sheet (PROMICE) is funded by the Geological Survey of Denmark and Greenland (GEUS) and the Danish Ministry of Climate, Energy and Building under Danish Cooperation for Environment in the Arctic (DANCEA), and is conducted in collaboration with the National Space Institute (DTU Space) and Asiaq (Greenland Survey). The NUK and KAN stations were/are (co-)funded by the Greenland Climate Research Centre (GCRC) and the Greenland Analogue Project (GAP), respectively. Thanks to T. Mote for making the passive microwave product (PMP) available. This study was funded by DK ESA-PRODEX under the CryoClim project.

\section{References}

Ahlstrøm, A.P. et al. 2008: A new programme for monitoring the mass loss of the Greenland ice sheet. Geological Survey of Denmark and Greenland Bulletin 15, 61-64.

Box, J.E., Fettweis, X., Stroeve, J.C., Tedesco, M., Hall, D.K., Steffen, K. 2012: Greenland ice sheet albedo feedback: thermodynamics and atmospheric drivers. The Cryosphere 6, 821-839.
Citterio, M., Robert S. Fausto, R.S., Ahlstrøm, A.P., Andersen, S.B., van As, D., Charalampidis, C. \& Veicherts, M. 2015: Automatic weather stations for basic and applied glaciology. Geological Survey of Denmark and Greenland Bulletin 33, 69-72.

Cuffey, K.M. \& Paterson, W.S.B. 2010: The physics of glaciers, 693 pp. Burlington: Butterworth-Heinemann/Elsevier.

Dumont, M. et al. 2014: Contribution of light-absorbing impurities in snow to Greenland's darkening since 2009. Nature Geoscience 7, 509512.

Fausto, R.S., Mayer, C. \& Ahlstrøm, A.P. 2007: Satellite-derived surface type and melt area of the Greenland ice sheet using MODIS data from 2000 to 2005. Annals of Glaciology 46, 35-42.

Hall, D.K., Comiso, J.C., DiGirolamo, N.E., Shuman, C.A., Key, J.R. \& Koenig, L.S. 2012: A satellite-derived climate-quality data record of the clear-sky surface temperature of the Greenland ice sheet. Journal of Climate 25, 4785-4798.

IPCC 2013: Climate Change 2013: The physical science basis. Working Group I contribution to the Fifth Assessment Report of the Intergovernmental Panel on Climate Change, 1535 pp. Cambridge University Press.

McGrath, D., Colgan, W., Bayou, N., Muto, A. \& Steffen, K. 2013: Recent warming at Summit, Greenland: global context and implications. Geophysical Research Letters 40, 2091-2096.

Mote, T.L. 2007: Greenland surface melt trends 1973-2007: evidence of a large increase in 2007. Geophysical Research Letters 34, L22507.

Nghiem, S.V., Hall, D.K., Mote, T.L., Tedesco, M., Albert, M.R., Keegan, K., Shuman, C.A., DiGirolamo, N.E. \& Neumann, G. 2012: The extreme melt across the Greenland ice sheet in 2012. Geophysical Research Letters 39, L20502.

Tedesco, M., Fettweis, X., Mote, T., Wahr, J., Alexander, P., Box, J.E. \& Wouters, B. 2013: Evidence and analysis of 2012 Greenland records from spaceborne observations, a regional climate model and reanalysis data. The Cryosphere 7, 615-630. 